\title{
LINUS PAULING: POR QUE VITAMINA C?
}

\author{
Ricardo Ferreira \\ Departamento de Química Fundamental, Centro de Ciências Exatas e da Natureza, Universidade Federal de Pernambuco, \\ 50670-901 Recife - PE
}

Recebido em 9/5/03; aceito em 10/6/03

LINUS PAULING: WHY VITAMIN C? The overwhelming interest shown by Pauling in the last twenty years of his life on the use of daily megadoses of Vitamin $\mathrm{C}$ for the maintenance of good-health is explained by a psyco-analytic approach, on the basis of documented stages of his life, from early boyhood to senior citizen.

Keywords: Pauling; vitamin C.

As novas gerações de estudantes e professores de Química, e o público em geral, associam cada vez mais o nome de Pauling ao uso da Vitamina $\mathrm{C}$ na dieta, em quantidades muito maiores do que as $60 \mathrm{mg}$ diárias recomendadas pela Medicina tradicional como fator anti-escorbútico e, dessa maneira, tendem a esquecer as grandes contribuições do pesquisador mais influente na Química, desde que Lavoisier escreveu o seu Tratado Elementar de Química em 1789.

Este interesse pelo uso médico do íon ascorbato em doses cada vez maiores começou em Pauling quando ele tinha quase 70 anos, com o seu conhecido trabalho no Proc. Nat. Acad. Sci. USA (1970, 67, 1643). Nesta publicação Pauling faz algumas considerações sobre o fato surpreendente de que, entre os mamíferos, somente a cobaia e os primatas não sintetizam ácido ascórbico através do seu metabolismo, necessitando da presença deste redutor como fator alimentar essencial, isto é, como uma Vitamina. Pauling atribuiu esta característica a uma mutação que foi favorecida nas condições ambientais em que isto teria ocorrido com um nosso ancestral, inserido em um ambiente no qual o ácido ascórbico deveria ser suficientemente abundante. Pauling propôs então que o íon ascorbato deveria representar um papel mais importante para as funções vitais do que o reconhecido mas limitado papel de co-fator na enzima prolilhidroxilase, que acelera a conversão do pro-colágeno em colágeno, proteína que promove a ligação ente as células dos tecidos conjuntivos.

A partir de 1970, de fato, e praticamente até a sua morte em agosto de 1994, com 93 anos de idade, a campanha em favor de megadoses diárias de Vitamina $\mathrm{C}$, monopolizou praticamente todas as forças de Pauling, que, inclusive, se afastou dos grandes Centros de Investigação Científica e criou um pequeno Instituto privado, o "Linus Pauling Institute for Sciences and Medicine", em Palo Alto, Califórnia.

Verdade que, mesmo depois da perda, em dezembro de 1981, da sua mulher Ava Helen (vítima de câncer), Pauling ainda deu algumas contribuições, por exemplo, à Química Estrutural, com os seus estudos sobre os "quase-cristais", e não diminuiu suas atividades na luta pela Paz Mundial.

Mas a grande maioria dos químicos e biólogos, em particular aqueles seus amigos e admiradores, jamais se conformou com esta atitude de Pauling, que muitos atribuíam a uma obstinação inexplicável, uma verdadeira mania, contrária a um grande número de estudos clínicos. Aliás, em contrapartida pode-se dizer que a classe médica, especialmente nos Estados Unidos, reagiu de forma violenta mesmo com respeito aos primeiros trabalhos de Pauling, realizados com base na sua primeira proposta, de 1970.

Faz algum tempo que, levando em conta numerosos episódios da sua vida ${ }^{1}$, a começar dos seus primeiros anos no Oregon, temos tentado esboçar uma teoria psicanalítica para a conduta de Pauling em prol do uso extensivo da Vitamina C, reforçada, na sua idade mais madura, por razões ideológicas que o fizeram duvidar dos verdadeiros propósitos da "American Medical Association" e lutar pelo estabelecimento de um Serviço Nacional de Saúde.

Descrevemos a seguir algumas fases deste processo:

a) Pauling tinha uma grande admiração por seu pai, farmacêutico em Condon e Portland, Sr. Herman Pauling (1876-1910). Em 1910, um mês antes do seu falecimento prematuro, Herman Pauling escreveu uma carta ao jornal "The Portland Oregonian", na qual afirmava que seu filho de 9 anos, Linus, tinha uma mente excepcional ("já leu e compreendeu muito bem "A Origem das Espécies" de Darwin”), e fazia um apelo para a constituição de um fundo especial que garantisse a manutenção de Linus em uma Universidade. Herman Pauling, como tantos operadores de "drug stores" naquela época, não era diplomado em Farmácia, e vendia um "Dr. Herman's Syrup", um cura-tudo típico daqueles tempos. Pergunta: não seria, a vitamina C de 1970, o xarope do Dr. Herman de 1910?

b) Desde o falecimento do pai, Pauling e sua mãe desenvolveram um antagonismo mútuo. Lucy Isabelle, preocupada com as finanças domésticas, viúva com duas filhas mais moças do que Linus, insistia para que Pauling, depois de cursar a "high school", arranjasse um emprego que lhe permitisse ajudar a mãe e irmãs.

c) Felizmente a percepção de alguns dos seus professores de Química do "Oregon Agricultural College", para onde Pauling entrou no outono de 1917 (tinha 16 anos) salvou o futuro cientista, pois ele foi proposto e aceitou, no terceiro ano (ele quase perdera o segundo ano, trabalhando como operário construtor de estradas) o cargo de Instrutor de Química Analítica, com um salário, razoável para a época, de US\$100.00 mensais.

d) Em 1942-43 Pauling foi acometido de uma grave doença renal, com albuminúria e febre (provavelmente doença de Bright), da qual foi tratado com marcado sucesso por métodos não ortodoxos (uma dieta pobre em proteínas) por Dr. Thomas Addis. Foi a Thomas Addis que Pauling dedicou o seu famoso livro didático, 
General Chemistry (1947). E logo correu em defesa do Dr. Addis, acusado de simpatias comunistas pelo Comitê de Atividades NãoAmericanas do Congresso em Washington, e muito criticado pela maioria dos seus colegas médicos.

e) Quando da sua campanha vitoriosa para Presidente da "American Chemical Society", em 1949, Pauling foi atacado pela "American Medical Association", uma antecipação do que viria depois com relação a seu posicionamento sobre a Vitamina C.

Somente considerando esses fatores poderemos compreender plenamente sua tardia defesa de grandes doses de Vitamina $\mathrm{C}$, uma substância redutora natural, que se encaixava perfeitamente na sua concepção de uma Medicina Ortomolecular, onde deveriam prevalecer fármacos com moléculas semelhantes àquelas componentes da nossa bioquímica, adaptados ao longo da evolução dos seres vivos.

Somente assim poderemos resgatar, em toda a sua plenitude, as grandes contribuições de Pauling à Química Estrutural, à Biologia Molecular, à Evolução Molecular, bem como a sua luta contra as desigualdades de renda (como ele gostava de dizer) e a favor da Paz.

\section{REFERÊNCIA}

Serafim, A.; Linus Pauling, Paragon House, New York, 1991. 